\title{
Impacts of Community Pharmacists on Self-medication Management among Rural Dwellers, Kwara State Central, Nigeria
}

\author{
Shakirat I. Bello ${ }^{1}$ and Ibrahim K. Bello ${ }^{2}$ \\ ${ }^{1}$ Department of Clinical Pharmacy and Pharmacy Practice, Faculty of Pharmaceutical Sciences, \\ University of Ilorin, Ilorin, Nigeria. \\ ${ }^{2}$ Department of Pharmacy, University of Ilorin Teaching Hospital, Ilorin, Nigeria.
}

\begin{abstract}
The role of pharmacist has not only advanced from medication dispensing but also to direct patient care and pharmaceutical interventions aiming at enhancing the populace wellbeing. The objective of this research was to assess the impact of rural community pharmacist interventions on self-medications and disease prevalence among rural settings in the Kwara State Central, Nigeria. A descriptive, cross-sectional study was conducted in eight rural communities with a pre-piloted questionnaire. Data obtained from respondents were computed with Statistical Package for Social Sciences (SPSS) Version 16 using descriptive analysis procedures, and relationships between variables were tested using the chi square. Respondents between the age of 40 and 50 years dominated with $42.3 \%$ and majority (88.1\%) of the rural residents were illiterates. Farming was the major occupation of the respondents and survived on less than ten thousand naira Nigeria money (\$63) per month. Among the combinations of drugs abused by the respondents, the regimen containing combination of prednisolone, diclofenac and paracetamol had the highest users. The least used combination was ibuprofen, diclofenac plus prednisolone. These combinations were taken twice daily by the majority participants. The most common reasons given for self-medications were osteoarthritis (31.1\%), poverty (17.4\%), general body pain (14.3\%), inadequate of health facilities (4.6\%), ignorance (4.3\%) among others. The intervention offered by the pharmacists had reduced the mean systolic blood pressure significantly $(P<0.05)$ from $161 \mathrm{mmHg}$ to $129 \mathrm{mmHg}$ and diastolic blood pressure from $104 \mathrm{mmHg}$ at baseline to $86 \mathrm{mmHg}$. Postintervention evaluation revealed the impact of the pharmacists, as the respondents with dyspepsia at baseline significantly $(P<0.05)$ reduced from 220 to 53 participants.
\end{abstract}

Key words: Pharmacist interventions, drug combinations, prevalent diseases, Oke-Oyi metropolis

\section{INTRODUCTION}

Community pharmacists in the rural/remote areas are usually turn to for advice in the treatment of minor illnesses, and make appropriate recommendations, including referral to hospitals. ${ }^{1-5}$ Abuse of medicine has been a bane and major constraint in ensuring safe and effective use of essential medicines. Self medication is the self care initiative of obtaining and consuming drugs without medical advice either for diagnosis, prescription or surveillance of treatment. ${ }^{6}$

Correspondence to: Shakirat I. Bello E-mail: sibello10@yahoo.com

Dhaka Univ. J. Pharm. Sci. 12(1): 1-9, 2013 (June)
Prevalence of drug abuse has been associated with self medication of drugs obtained over the counter, consumption of left-over medicines, sharing medicines with relatives or friends or using left-over medicine stored at residential places. ${ }^{7,8}$ Previous studies have shown that self-medication practices are common in women and students. ${ }^{9}$ Lack of medication counselling and essential drug information could lead to improper self-medications and non-adherence to drug regime, leading to therapeutic failure and even death in the rural areas. Previous studies conducted on community pharmacy practice and self-medication in Nigeria were in the urban settings such as Abuja, ${ }^{10}$ Calabar, ${ }^{11}$ Ibadan ${ }^{12}$ as well as Aba, Benin and Ilorin. ${ }^{13}$ The concept of rural pharmaceutical care and self medication is neither well developed nor 
adequately documented in Nigeria. Against these backdrops, research on the pharmacist-delivered medication therapy management of diseases and peculiar health needs of rural dwellers are very imperative. This study was therefore conducted to assess the impact of rural community pharmacist interventions on self-medications and disease prevalence among rural settings in the Kwara State Central, Nigeria.

\section{MATERIALS AND METHOD}

Study location. Oke Oyi (Latitude $8^{0} 5^{\prime} \mathrm{N}$ and Longitude $4^{0} 5^{\prime} \mathrm{E}$ ) is the headquarters of Ilorin East Local Government Area, Kwara State, Nigeria with a landed area of $486 \mathrm{~km}^{2}$ with a population of 204,310 as at 2006 Population Census. It is surrounded by eight villages (Baba Dudu, Okeemi, Ibudo Oyo, Elesin meta, Gbadamu, Onikoko, Korowa Ologi and Loosa) and other hamlets. The villages had no basic health facilities except some patent medicine vendors and only one pharmaceutical chemist in Oke Oyi that serves all the surrounding communities since 1998.

Study design. A descriptive, cross-sectional survey was chosen as the means to assess the impact of rural community pharmacist on drug selfmedications and disease prevalence among rural communities. The study was conducted between September, 2011 and February, 2013 with 730 participants aged from 30 years and above. The respondents are regular clients patronizing the rural community pharmacy in Oke Oyi over ten years. Data were collected using questionnaire and personal interview.

Data collection. Data were collected using a structured pre-piloted and validated questionnaire containing both closed-and open-ended questions. The questionnaire includes 32 questions covering three sections; (i) demographic information of the respondents, (ii) self medication usage and (iii) prevalent illnesses. A pilot study was conducted on 150 respondents for 6 weeks to validate the research instrument. Personal interview and filling of the survey forms were carried out for the unschooled participants using the local languages (Yoruba, Hausa and Pidgin English). Pharmaceutical interventions on adequate drug information and counselling on appropriate health management strategies including hypertension, osteoarthritis, dyspepsia, malaria and nutritional deficiency were provided at the baseline and bi-monthly for eighteen months. During the period of the study, 3,112 interventions were made with 818 pharmaceutical interventions on 176 hypertensive respondents while 801 interventions were carried out on 220 participants with dyspepsia. Respondents with ostearthritis, malaria, anaemia and insomnia were given 678, 522, 122 and 171 interventions respectively. Body weight, height, body temperature and blood pressure were also measured routinely at every visit of participants to the pharmacy by the researchers.

Data analyses. The data obtained from respondents were analysed with Statistical Package for Social Sciences (SPSS) Version 16 using descriptive analysis procedures including the frequencies, means, standard deviations and percentages. Relationships between variables were tested using the chi-square.

\section{RESULTS}

Table 1 contains the data on the demographic characteristics of 730 respondents studied, of which one third were males and the rest $69.9 \%$ females. Respondents between the age of 40 and 50 years dominated with $42.3 \%$, followed by 51 60 years $(28.4 \%)$ and $30-39$ years $(20.1 \%)$. Twothirds of the respondents were married and $24.8 \%$ single. Majority of the rural residents were unschooled $(88.1 \%)$, primary and secondary school certificate holders were $6.9 \%$ and $5.0 \%$ respectively. None of the respondents attended tertiary institution. More than half of the studied participants engaged in farming. One fifth of the respondents were business men and women, while few of them engaged in fishing and cattle rearing.. Almost all the participants speak Yoruba language, followed by Hausa, Fulani and Bassa languages. Larger parts of the respondents were Muslims, less than five percent were Christians, while others were traditional religious believers. More than half of the participants were on self medications for above ten years, one third between one and five years, while less than one fifth were on 
drug abuse for at least one year. More than half of respondents were addicted to the consumption of kola nuts, snuffs, cigarettes and sometimes alcohols. Half of the rural residents in the study earned less than ten thousand Nigeria money (\$63) per month. Self- medication was found to be common among the rural people and it was not found to be associated $(P>0.05)$ with any of the characteristics of the demographic of the respondents (Table 2).

Table 1. Demographic characteristics of the respondents.

\begin{tabular}{|c|c|c|}
\hline Characteristics & Status & Number $=730(\%)$ \\
\hline \multirow[t]{2}{*}{ Gender } & Male & $222(30.4 \%)$ \\
\hline & Female & $508(69.6 \%)$ \\
\hline \multirow[t]{4}{*}{ Age (years) } & $30-39$ & $147(20.1 \%)$ \\
\hline & $40-50$ & $309(42.3 \%)$ \\
\hline & $51-60$ & $207(28.4 \%)$ \\
\hline & 61 and above & $67(9.2 \%)$ \\
\hline \multirow[t]{2}{*}{ Marital status } & Married & $549(75.2 \%)$ \\
\hline & Unmarried & $181(24.8 \%)$ \\
\hline \multirow[t]{4}{*}{ Education } & Tertiary & None \\
\hline & Secondary & $36(5.0 \%)$ \\
\hline & Primary & $51(6.9 \%)$ \\
\hline & Illiterates & $643(88.1 \%)$ \\
\hline \multirow[t]{3}{*}{ Occupation } & Agriculture & $502(68.8 \%)$ \\
\hline & Businessmen/women & $149(20.4 \%)$ \\
\hline & Others & $79(10.8)$ \\
\hline \multirow[t]{3}{*}{ Ethnicity } & Yoruba & $669(91.7 \%)$ \\
\hline & Hausa/Fulani & $47(6.4 \%)$ \\
\hline & Bassa & $14(1.9 \%)$ \\
\hline \multirow[t]{3}{*}{ Religion } & Islam & $688(94.3 \%)$ \\
\hline & Christianity & $34(4.6 \%)$ \\
\hline & Others & $8(1.1 \%)$ \\
\hline \multirow[t]{3}{*}{ Duration of medication (years) } & $<1$ & $(13.3 \%)$ \\
\hline & $1-5$ & $(34.5 \%)$ \\
\hline & $6-10$ & $(52.2 \%)$ \\
\hline \multirow[t]{5}{*}{ Lifestyle habits } & Kolanut consumers & $(56.7 \%)$ \\
\hline & Snuff inhalers/suckers & $(15.8 \%)$ \\
\hline & Smokers & $(4.9 \%)$ \\
\hline & Alcoholics & $(2.1 \%)$ \\
\hline & None of above & $(10.5 \%)$ \\
\hline \multirow[t]{3}{*}{ Income /month (naira) } & $<10,000$ & $374(51.3 \%)$ \\
\hline & $10,000-20,000$ & $236(32.3 \%)$ \\
\hline & Above 20,000 & $120(16.4 \%)$ \\
\hline
\end{tabular}

Table 3 shows that the regimen containing prednisolone plus diclofenac and paracetamol had the highest users (31.1\%). This was followed by tramadol plus ibuprofen plus paracetamol combination $(25.0 \%)$, ibuprofen plus prednisolone plus paracetamol (18.1\%) and piroxicam plus ibuprofen plus paracetamol (15.4\%). The least abused drug combination was ibuprofen plus diclofenac plus prednisolone (10.4\%). More than half of the respondents had two times dose frequency (morning and afternoon) for their abused medications. The once daily regimen was commonly used by $25 \%$ of the respondents. Only few participants were on once daily cocktail (Table 4). Table 5 shows the rationale behind self-medications. The foremost reason was osteoarthritis. Other justifications were poverty, general body pain, fever, low back pain, lack of health facilities and ignorance. Malaria was the most prevalent disease in the communities, with dyspepsia ranking second and high blood pressure third. Others were insomnia and anaemia (Table 6). 
At baseline of the present study, the mean systolic blood pressure of respondents was $161 \mathrm{mmhg}$ (Table 7). The intervention offered by the pharmacist had reduced the value significantly $(P<0.05)$ to 129 mmhg. The diastolic blood pressure also diminished from $104 \mathrm{mmhg}$ at baseline to $86 \mathrm{mmhg}$ at postintervention. Also, at baseline, two hundred and twenty (220) respondents had dyspepsia due to self medication of analgesics. Post-intervention evaluation showed the drastic improvement impacted by the pharmacist as the respondents with dyspepsia had significantly $(P<0.05)$ reduced to 53 . Insomnia was recognised as a medical problem among the respondents (42) at baseline study, but at postintervention, this value was dropped to five.

Table 2. Prevalence of self medication practice among respondents.

\begin{tabular}{|c|c|c|c|}
\hline Characteristics & Prevalence $(\%)$ & $\chi^{2}, \mathrm{df}$ & $\mathrm{P}$ value \\
\hline Gender & & $2.351,1$ & 0.271 \\
\hline Male & 72.4 & & \\
\hline Female & 85.1 & & \\
\hline Age (years) & & $7.672,3$ & 0.453 \\
\hline $30-39$ & 83.6 & & \\
\hline $40-50$ & 80.5 & & \\
\hline $51-60$ & 54.6 & & \\
\hline 61 and above & 40.3 & & \\
\hline Marital status & & $3.561,1$ & 0.251 \\
\hline Married & 86.2 & & \\
\hline Unmarried & 80.3 & & \\
\hline Education & & $3.529,3$ & 0.083 \\
\hline Tertiary & - & & \\
\hline Secondary & 70.6 & & \\
\hline Primary & 68.9 & & \\
\hline Illiterates & 86.7 & & \\
\hline Occupation & & $2.382,2$ & 0.145 \\
\hline Agriculture & 86.6 & & \\
\hline Businessmen/women & 75.8 & & \\
\hline Others & 78.4 & & \\
\hline Ethnicity & & $3.415,2$ & 0.073 \\
\hline Yoruba & 83.5 & & \\
\hline Hausa/Fulani & 86.3 & & \\
\hline Bassa & 85.3 & & \\
\hline Religion & & $2,618,2$ & 0.341 \\
\hline Islam & 76.7 & & \\
\hline Christianity & 68.5 & & \\
\hline Others & 74.2 & & \\
\hline Duration of medication (years) & & $4.173,2$ & 0.152 \\
\hline$<1$ & 78.3 & & \\
\hline $1-5$ & 80.4 & & \\
\hline $6-10$ & 86.3 & & \\
\hline Lifestyle habits & & $6.291,4$ & 0.076 \\
\hline Kolanut consumers & 80.4 & & \\
\hline Snuff inhalers/suckers & 83.6 & & \\
\hline Smokers & 85.3 & & \\
\hline Alcoholics & 86.2 & & \\
\hline None of above & 67.8 & & \\
\hline Income /month (Naira) & & $3,719,2$ & 0.241 \\
\hline$<10,000$ & 85.4 & & \\
\hline $10,000-20,000$ & 78.3 & & \\
\hline Above 20,000 & 75.7 & & \\
\hline
\end{tabular}


Table 3. Self-medication combinations utilized by rural communities in Oke Oyi metropolis.

\begin{tabular}{|c|c|}
\hline Tablet strength (Number of tablets taken per dose) & Number $=730(\%)$ \\
\hline Ibuprofen $400 \mathrm{mg}(2)+$ Prednisolone $5 \mathrm{mg}(2)+$ Paracetamol $500 \mathrm{mg}$ (3) & $132(18.1 \%)$ \\
\hline Prednisolone $5 \mathrm{mg} \mathrm{(2)} \mathrm{+} \mathrm{Diclofenac} \mathrm{Sodium} 50 \mathrm{mg}$ (2) + Paracetamol $500 \mathrm{mg}$ (3) & $227(31.1 \%)$ \\
\hline Piroxicam 20 mg (1) + Ibuprofen 400 mg (2) + Paracetamol 500 mg (3) & $112(15.4 \%)$ \\
\hline Ibuprofen $400 \mathrm{mg}(2)+$ Diclofenac Sodium $50 \mathrm{mg}(1)+$ Paracetamol $500 \mathrm{mg}(2)$ & $76(10.4 \%)$ \\
\hline Tramadol $100 \mathrm{mg}$ (1) + Ibuprofen $400 \mathrm{mg}$ (2) + Paracetamol $500 \mathrm{mg}$ (3) & $183(25.0 \%)$ \\
\hline
\end{tabular}

\section{DISCUSSION}

The pharmacist's role has evolved over time, moving from traditional medication dispensing to involvement in direct patient care to the delivery of pharmaceutical care with a focus on enhancing medication appropriateness and preventing drugrelated problems. ${ }^{14}$ In the present study, more than three quarter of the respondents were illiterates. This is in line with the findings of ${ }^{15}$ that low level of literacy on many rural communities can be extremely arduous. Majority of the rural residents in the present work were married women, signifying that women consult medical experts for their ailments than the

Table 4. Dose frequency of self-medication combinations utilized by rural communities in Oke Oyi metropolis.

\begin{tabular}{lc}
\hline Dose frequency & Number $=730(\%)$ \\
\hline Once daily & $180(24.6 \%)$ \\
Twice daily & $499(68.4 \%)$ \\
Thrice daily & $51(7.0 \%)$ \\
\hline
\end{tabular}

Table 5. Reasons for self-medications among rural communities in Oke Oyi metropolis.

\begin{tabular}{lc}
\hline Reasons & Number $=730(\%)$ \\
\hline General body pain & $104(14.3 \%)$ \\
Lack of health facilities & $34(4.6 \%)$ \\
Headache & $38(5.2 \%)$ \\
Fever & $91(12.5 \%)$ \\
Low back pain & $77(10.6 \%)$ \\
Osteoarthritis & $227(31.1 \%)$ \\
Poverty & $127(17.4 \%)$ \\
Ignorance & $31(4.3 \%)$ \\
\hline
\end{tabular}

Table 6. Other prevalent illnesses among rural communities in Oke Oyi metropolis.

\begin{tabular}{lc}
\hline Illnesses & Number $=730(\%)$ \\
\hline Dyspepsia & $220(30.1 \%)$ \\
Anaemia & $44(6.0 \%)$ \\
High blood pressure & $176(24.1 \%)$ \\
Malaria & $248(34.1 \%)$ \\
Insomnia & $42(5.7 \%)$ \\
\hline
\end{tabular}

Table 7. Blood pressure before and after pharmacist's intervention among the respondents.

\begin{tabular}{lccc}
\hline \multirow{2}{*}{ Parameter studied } & \multicolumn{2}{c}{ Mean (standard deviation) } \\
\cline { 2 - 4 } & $\begin{array}{c}\text { Pre- } \\
\text { intervention }\end{array}$ & $\begin{array}{c}\text { Post- } \\
\text { intervention }\end{array}$ & P-value \\
\hline $\begin{array}{l}\text { Systolic BP } \\
(\mathrm{mmHg})\end{array}$ & $161(26)$ & $129(18)$ & $<0.05$ \\
$\begin{array}{l}\text { Diastolic BP } \\
(\mathrm{mmHg})\end{array}$ & $104(13)$ & $86(10)$ & $<0.001$ \\
$\begin{array}{l}\text { Number of } \\
\text { respondents with } \\
\text { dyspepsia }\end{array}$ & $220(28)$ & $53(7)$ & $<0.05$ \\
$\begin{array}{l}\text { Number of } \\
\text { respondents with } \\
\text { insomnia }\end{array}$ & $42(5)$ & $5(0.6)$ & $<0.05$ \\
\hline
\end{tabular}

$\mathrm{BP}=$ Blood Pressure

men ${ }^{16}$ also reported that in most communities and households across the world, women are the principal carers. Respondents between the age of 40 years and over dominated the present study. This is an attribute of rural communities which are known to be populated by the elderly in Nigeria probably rural urban drift by the youth. The aged people have comorbidities due to physiological changes in the body system as the age advances. These anomalies probably necessitated frequent patronage of the community pharmacy by the aged. Rural residents engaged mostly in agricultural activities as revealed by the present study. In upkeep with present study was the report of ${ }^{17}$ that agriculture remains the predominant rural occupation in Nigeria. Contrary, in Europe and America, agriculture has been eroded as the determiner of economic and social relations of rural areas. ${ }^{18}$ Farming, being labour intensive and due to inadequacy of agricultural machineries to support the respondents, had predisposed them to incessant and excessive consumptions of various classes of analgesics over a long period of time.

Only a small portion of the participants take alcohol in all the studied communities. The reason given by the respondents was that alcohol consump- 
tion is forbidden by their religion of Islam. They claimed alcohol could result in memory impairment which reduces concentration needed to observe their five daily prayers as ordained in Islam. Kola nut is known to be socially acceptable among the respondents and hence more than half were involved in its consumption. This was supported by ${ }^{19}$ that kola nut is preferred among African Muslims, who are forbidden to drink alcohol. The caffeine component of kola nut could induce insomnia, dyspepsia and transient high blood pressure. In line with present study $^{19,20}$, reported that Kola nut should not be used by patients with a history of high blood pressure, heart trouble, palpitations, seizures, insomnia, heart disease, high cholesterol, stroke and stomach or duodenal ulcers because it increases gastric juice production. To avert the respondents of the chronic adverse effects of kola nut, the pharmacist counselled on gradual withdrawal from habitual chewing of kola nut to bitter kola. ${ }^{21}$ Earlier reports recorded no side effect to the regular intake of bitter kola, and it was all round medicinal. ${ }^{22}$ It was also reported that bitter kola has antioxidant properties, used as tonic for the liver and gall bladder as it detoxifies the body system.

The means of sustenance among the participants is mainly farming, which is seasonal. The respondents were financially buoyant during raining season when the sales of their farm products were actively on. In dry season, they were financially handicapped because nothing to offer for sale but preparation of lands for next planting season. This phenomenon justified why rural residents were in abject poverty living on less than ten thousand naira per month (\$63). In agreement with present research, Food and Agriculture Organization ${ }^{23}$, has focused special attention on developing rural areas, where most of world's poor and hungry people are living, not only to carry its mandate to raise the levels of nutrition, but also to improve agricultural productivity and living conditions of rural populations. In Nigeria, available evidences showed that income from farming activities has continued to decline due to economic shock and environmental uncertainties. Level of poverty among families solely dependent on farming is reportedly high compared to families with diversified livelihood opportunities. ${ }^{15}$

The prevalence of self-medication among the rural dwellers has no association the demographic parameters studied. The respondents were involved in self-medications most especially analgesics in the classes of Non-Steroidal Anti-inflammatory Drugs (NSAIDs), aniline and opioids. These drugs were consumed in excess with overlapping side effects. NSAIDs when taking within normal range are useful in the treatment of chronic disease accompanied by pain and inflammation. The overdose and prolong use could result into dyspepsia, insomnia, depression, headache, fluid retention and high blood pressure as demonstrated in this study. Overviews of clinical trial data indicated that the blood pressure of patients with controlled hypertension can be raised by 3 to $6 \mathrm{~mm}$ $\mathrm{Hg}$ during concurrent treatment with NSAIDs, and could result to stroke, end-stage renal disease, or congestive heart failure. ${ }^{23}$ The use of these drugs has been linked to an unexpectedly high incidence of ulcer complications, and a history of peptic ulcer disease is common in such cases. ${ }^{25}$ This study was further supported by ${ }^{26}$ who demonstrated the adverse effects of renal failure and hypertension among the users. Indefinite use of paracetamol, a class of aniline analgesic was indulged by the respondents to be a daily routine drug without medical need. They consumed an overdose of $4.5 \mathrm{~g}$ per day (three tablets three times daily). The respondents claimed that two tablets of paracetamol as a dose is inefficacious for the type of task they performed. The rational was that habitual use of paracetamol leads to decrease in threshold for pain (endurance level for pain) among the rural residents. Further problems arising from paracetamol abuse are upper gastrointestinal tract bleeding, liver failure, kidney dysfunction and untimely death. Though these symptoms developed gradually, as failure of these organs appear at advance stage of the disease. The mechanism of multiple organ damage particularly the liver and kidney from excessive use of paracetamol, is not from the drug itself but from one of its metabolites, $\mathrm{N}$-acetyl-p-benzoquinoneimine (NAPQI). ${ }^{27}$ 
In the near future the respondents could be victims of major organ damage (especially liver) if not for pharmacist intervention that encourages the respondents' consultation before purchasing paracetamol. This result was also supported by Food and Drug Administration ${ }^{28}$ who reported that paracetamol tablets used in excess (overdose or continuous use) can prove fatal due to its many side effects some of which are very dangerous leading to failure of liver, kidney and ultimately death. In June 2009, an advisory committee of FDA recommended that new restrictions should be placed on paracetamol to help protect people from the potential toxic effects. The present study would sensitize Nigeria government to place such restrictions on paracetamol utilization by the general populace. Tramadol, an opioid analgesic approved for the relief of moderate to severe pain is associated with adverse effects of hypertension, paraesthesia, gastro intestinal disturbances, respiratory depression and psychiatric disorder. Tramadol is commonly abused at higher doses by these set of people and they claimed to energise them for vigorous activities. Prednisolone also is frequently abused by the studied population. The outcome of such misused could cause the side effects of peptic ulcers, hypertension, congestive heart failure and liver failure.

The additive effects of these drugs explained the rationale for the symptoms and other illnesses prevailing within the rural communities. The respondents gave the reasons for self medication abused as due to lack of health facilities, poverty and ignorance. The clinical pharmacist was able to play a versatile role in counselling the rural populace on the danger of self-medication. The intervention imparted on the respondents by the pharmacist had greatly improved the overall health status of the rural dwellers that represent more than one half of Nigeria citizens. National Population Commission ${ }^{29}$, previously reported that approximately two-thirds of the population live in rural areas.

Both systolic and diastolic blood pressure of the respondents had significantly reduced at $\mathrm{P}<0.05$ and well controlled to a manageable level after pharmacist intervention. To achieve this, pharmacist repeatedly counselled respondents on life style modifications such as reduction in dietary salt, seasoning foods and fatty meat. They were encouraged to engage in high consumption of fresh fruits, vegetable, non-saturated fatty milk, sea foods, enough rest and regular exercise. Similar nutritional advice were made by ${ }^{30}$ This study is in agreement with $^{31}$ that when community pharmacists are trained and included as members of the primary care team, significant improvements in blood pressure control, quality of life, and patient satisfaction can be achieved in the health sector. The number of respondents with dyspepsia had declined after pharmacist intervention. The people were made to know that excessive consumption and prolonged use of analgesics was responsible for the development of dyspepsia, hypertension, insomnia and headache. They were also advised to stop self medication, and consult the pharmacist for their drug requirements.

As a result of consistent drug counselling and advice on lifestyle modifications embarked upon by the community pharmacist, the respondents had developed confidence in the pharmacist, in that rarely will they purchase drugs (even over the counter drugs) at the premise without the pharmacist's consent. However, several studies have highlighted that availability of pharmacist and provision of counselling to the patients can increase patient compliance with the therapy. ${ }^{14,32}$ The present research study shows the relevance of rural pharmacist in improving the health status of the people at the grassroots. For pharmacists to contribute immensely to development of healthcare system in Nigeria, the Federal Government of Nigeria should create more schools of pharmacy in both federal and state universities. The study of reported that the low availability of pharmacists in many developing countries is exacerbated by geographical distribution disparity between the rural and urban areas. ${ }^{33}$ As further reported by Akhimien et al. ${ }^{34}$ that there is shortage of manpower in pharmacy profession in Nigeria. 


\section{CONCLUSION}

This study revealed that self-medication is prevalent among the rural dwellers and ignorance due to illiteracy has been a bane in the rural communities. Pharmacist interventions on selfmedication of drugs however greatly enhanced patient healthcare in the rural communities.

\section{RECOMMENDATION}

There is a need for educational interventions targeting the pharmaceutical service provider, and to explore expanded pharmaceutical care roles in the rural community pharmacy facilities. Diagnostic and drug supply roles in the health and pharmaceutical sector should be rationalized in the rural places where these services are sufficiently developed. The strengthening of referral systems from community pharmacies is also a necessity. More pharmacists should be produced and employed to enhance the quality of healthcare in Nigeria. The existing Nigerian laws regarding the use and sale of over the counter drugs, prescribed and non-prescribed drugs should also be strengthened to ensure rational use of medicines.

\section{DECLARATION OF INTEREST}

The authors report no conflicts of interest. The authors are responsible for the content and writing of the paper.

\section{REFERENCES}

1. Ballantyne, P.J. 2007. The role of pharmacists in primary care. BMJ 334, 1066-1067.

2. Radford A., Richardson I., Mason M. and Rutledge S. 2009. The key role of sole community pharmacists in their local healthcare delivery systems: Rural Policy Brief A joint publication of the North Carolina Rural Health Research and Policy Analysis Center and The RUPRI Center for Rural Health Policy Analysis. pp. 345-350.

3. Ross L.A. and Bloodworth L.S. 2012. Patient-centered health care using pharmacist-delivered medication therapy management in rural Mississippi, J. Am. Pharm. Assoc., 52, 802-809.

4. Fakeye, T.O, Adisa, R. and Showande, S.J.S. 2012. Attitude and opinion of Nigerian community pharmacists to self medication practices. Afr. J. Pharm. Pharmacol. 6, 11471152.
5. Kelli, T., Fred, U. and Keith, M. 2013. Rural Pharmacy Closures: Implications for Rural Communities. RUPRI Center for Rural Health Policy Analysis, University of Iowa College of Public Health, Department of Health Management and Policy, 105 River St., N232A, Iowa City, IA 52242, (319) 384-3830. Available at http://www.public-health. uiowa.edu/ rupri

6. Phalke, V.D., Phalke, D.B. and Durgawale, P.M. 2006. Self medication practices in rural Maharashtra. Indian $J$. Community Med. 31, 34-5.

7. Indermitte, J., Reber, D., Beutler, M., Brunacher, R. and Hersberger, K.E. 2007. Prevalence and patient awareness of selected potential drug interactions with self medication. $J$. Clin. Pharm. Ther. 32, 149-159.

8. Goh, L.Y., Vitry, A.I., Semple, S.J., Esterman, A. and Luszcz, M.A. 2009. Self-medication with over-the-counter drugs and complementary medications in South Australia's elderly population. BMC Complement Altern. Med., 9, 42. http://www.biomedcentral.com/1472-6882/9/42

9. Fakeye, T.O., Adisa, R. and Olatunji, E. 2010. Self medication among hospitalized patients in selected secondary health facilities in South Western Nigeria. Pharm. Pract., 8, 233-237.

10. Okonkwo, A.D. and Okonkwo, U.P. 2010. Patent medicine vendors, community pharmacists and STI management in Abuja, Nigeria. Afr. Health Sci. 10, 253-265.

11. Arikpo, G.E., Eja, M.E., Enyi-idoh, K.H., Akubuenyi, f., Ngang, U., Akam, C. and Ekomabasi, I. 2011. Patterns of antibiotic drug use in Southern Nigeria communities. World J. Applied Sci. Tech. 3, 86-92.

12. Adisa R and Fakeye T (2006). Assessment of the knowledge of community pharmacists regarding common phytopharmaceuticals sold in South Western Nigeria. Trop. J. Pharm. Res. 5, 619-625.

13. Faduyile, T., Oparah, A.C. and Oreagba, I.A. 2012. Potentials of community pharmacists to Improve maternal, newborn and child health. West Afri. J. Pharm., 23, 76-86.

14. West, L.M., Cordina, M. and Cunningham, S. 2012. Clinical pharmacist evaluation of medication inappropriateness in the emergency department of a teaching hospital in Malta. Pharmacy Practice 10, 181-187.

15. Yusuf, R.O. and Ukoje, J.A. 2010. Recent observations on rural geographic research in Nigeria. Res. J. Environ. Earth Sci. 2, 76-81.

16. Felicity, S. 2004. Community pharmacy in Ghana: enhancing the contribution to primary health care. Health Policy and Planning, 19, 234-241.

17. Adebisi, A.D. 1998. An evaluation of public policies for rural development in Nigeria. Afric:. Revista do Centro Estudos Africanos. USP, S Paulo, 20-21, 146-152.

18. Redclift, N. and Whatmore, S. 1990. Household consumption and livelihood: Ideologies and issues in rural research. In: Marsden, T., P. Lowell and S.Whatmore, (Eds.), Rural restructuring. global processes and their responses. David Fulton, London. pp. 321-332. 
19. Absolute Herbal Health, 2012. The benefits of kola nut/Jamaican dried bizzy. http:www.absoluteherbal health. $\mathrm{com} /$ the -benefit-of nut/ amaican-dried- bizzy/

20. McPhilips, N. 2012. Kola nut: Nigeria's seed of togetherness. Vanguard, In Special Report on May 4, 2012. p.14.

21. Brai B. 2012. Vanguard Mobile Edition. Intake of bitter kola makes medication ineffective-experts. http:www.vangardngr. com/2012/09/intake-of bitter-kola-makes medicationineffective-experts/

22. Amaechi, E. 2012. Vanguard Mobile Edition. Intake of bitter kola makes medication ineffective-experts. http:www. vangardngr.com/2012/09/ intake-of bitter-kola-makes medication-ineffective-experts/

23. Food Agricultural Organization. 2010. World Programme for the Census of Agriculture 2010. A System of Integrated Agricultural Censuses and Surveys, FAO, Rome, Italy. pp 236-239.

24. Smith, M. 2009. Pharmacists' role in improving diabetes medication management. J. Diabetes Sci. Technol., 3, 175-9.

25. Soll, A.H., Weinstein, W.M., Kurata, J. and McCarthy, D, 1991. Nonsteroidal anti-inflammatory drugs and peptic ulcer disease. Ann. Intern. Med., 114, 307-19.

26. Walter, H. 2010. Nonsteroidal Anti-Inflammatory Drugs and the Kidney. Pharmaceuticals, 3, 2291-2321.

27. Bender, R.P., Lindsey, R.H. Jr, Burden, D.A. and Osheroff, N. 2004. N-acetyl-p-benzoquinone imine, the toxic metabolite of acetaminophen, is a topoisomerase II poison. Biochemistry. 43, 3731-9.
28. Food Drug Administration 2012. Limits Acetaminophen in Combination Prescription Products. Settlement Solutions. http://www.fda.gov/NewsEvents/Newsroom/press/Announce ments/ucm239894.htm.

29. National Population Commission. 2009. Nigeria demographic and health survey 2008. Abuja, Nigeria: National Population Commission and ICF Macro. pp 563571.

30. Sharon, A.C., Boggs, Linda, K. Massey1, Jill, E. Armstrong, William, R. Lassey and Jutta, C. Joseph. 1996. Education of Rural Community Pharmacists to Provide Nutrition Information. Am. J. Pharm. Educ. 60, 353-358.

31. Carter, B. and Barnette, D. 1997. Evaluation of hypertensive patients after care provided by community pharmacists in a rural setting. Pharmacotherapy, 17, 1274-1285.

32. Westerlund, T., Allebeck, P., Marklund, B., Andersson, I.L., Brånstad, J.O. and Sjöblom, M. 2003. Evaluation of a model for counselling patients with dyspepsia in Swedish community pharmacies. Am. J. Health Syst. Pharm. 60, 1336-1341.

33. Hassel, K. and Eden, M. 2006. Workforce update - Joiners, leavers, and practising and non-practising pharmacists on the 2005 register. The Pharm. J. 276, 40-42.

34. Akhimien, A. (2013) There's manpower shortage in pharmacy profession in Nigeria -Ex PSN President. http:www.tobore-mitovuorie.wordpress.com/2013/01/18/ there's-manpower-shortage-in-pharmacy-profession-innigeria-ex-psn-president/. 